\title{
LETTERS
}

\section{Tread carefully with \#MeToo in the medical profession}

I read this editorial ${ }^{1}$ with several misgivings; the \#MeToo movement has been a mixed blessing. On one hand, it has empowered women to come forward to report episodes of sexual misconduct. On the other hand, it has, in many peoples' minds, produced a mob mentality that assumes that all assertions of misconduct are automatically true. The whole discussion around sexual harassment and misconduct has become overheated. I think everyone agrees that it is important that we get this right.

The authors start with the interesting question of why no high-profile male physician has been called on the carpet by the \#MeToo movement, before continuing that medical training is awash with harassment and discrimination. This seems contradictory.

Of course, medical learning environments should be free of harassment. I looked at the references used in this commentary to get some idea of what kind of harassment is of concern. The first reference is a meta-analysis published in 2014) $)^{2}$ in which the authors reviewed data from 51 studies that met their criteria. From their findings, they concluded that harassment is a substantial problem in medical training. Across the different studies, $11 \%$ to $100 \%$ of participants reported harassment, $28 \%$ to $94 \%$ reported verbal abuse, $19 \%$ to $94 \%$ reported gender discrimination, $3 \%$ to $71 \%$ reported academic discrimination, $3 \%$ to $92 \%$ reported sexual discrimination, $3.8 \%$ to $94 \%$ reported racial discrimination and $3 \%$ to $100 \%$ reported physical abuse. My point is that the variability in these results is extremely wide, suggest- ing that the definitions used probably varied widely also. This casts doubt on any conclusion made from such a review.

Another concern is the recommendation that all medical leaders have training to correct their unconscious bias. Implicit bias testing and retraining is far from settled science. The following is a quote from a Psychology Today blog post by Dr. Lee Jussim: ${ }^{3}$

The research on so-called implicit bias has its serious critics. Almost everything about implicit bias is controversial in scientific circles. It is not clear what most implicit methods actually measure; their ability to predict discrimination is modest at best, their reliability is low; early claims about their power and immutability have proven unjustified.

I think we need to proceed with caution. It is not at all clear that we are dealing with an epidemic of harassment in our medical training. If we make decisions based on poor science and bad ideas, then the outcomes surely will not be good.

\section{Gary Satenstein MD}

Family physician, Wakefield, Que.

Cite as: CMAJ 2018 December 3;190: E1423. doi: 10.1503/cmaj.70919

\section{Reference}

1. Holroyd-Leduc JM, Straus SE. \#MeToo and the medical profession. CMAJ 2018;190:E972-3.

2. Fnais $\mathrm{N}$, Soobiah $\mathrm{C}$, Chen $\mathrm{MH}$, et al. Harassment and discrimination in medical training: a systematic review and meta-analysis. Acad Med 2014;89: 817-27.

3. Jussim L. Mandatory Implicit bias training is a bad idea [blog]. Psychology Today 2017 Dec. 2. Available: www.psychologytoday.com/ca/blog/rabble -rouser/201712/mandatory-implicit-bias-training -is-bad-idea (accessed 2018 Oct. 24).

Competing interests: None declared. 